\title{
STRONTIUM ISOTOPIC GEOCHEMISTRY OF INTRUSIVE ROCKS, PUERTO RICO, GREATER ANTILLES
}

\author{
LOIS M. JONES \\ Research and Development Department, Conoco Inc., Ponca City, OK 74601 (U.S.A.) \\ and \\ STEPHEN E. KESLER \\ Department of Geological Sciences University of Michigan Ann Arbor, MI 48109 (U.S.A.)
}

Received April 9, 1980

Revised version received May 19, 1980

\begin{abstract}
The strontium isotopic geochemistry is given for three Puerto Rican intrusive rocks: the granodioritic Morovis and San Lorenzo plutons and the Rio Blanco stock of quartz dioritic composition. The average calculated initial ${ }^{87} \mathrm{Sr} /{ }^{86} \mathrm{Sr}$ ratios are $0.70370,0.70355$ and 0.70408 , respectively. In addition, the San Lorenzo data establish a whole-rock isochron of $71 \pm 2 \mathrm{~m}$.y., which agrees with the previously reported $\mathrm{K}$ - $\mathrm{Ar}$ age of 73 m.y. Similarity of most of the intrusive rocks in the Greater Antilles with respect to their strontium isotopic geochemistry regardless of their major element composition indicates that intrusive magmas with a wide range of composition can be derived from a single source material. The most likely source material, in view of the available isotopic data, is the mantle wedge overlying the subduction zone.
\end{abstract}

\section{Introduction}

Considerable attention has been given to spatial and temporal variations in the composition of igneous rock in oceanic island arc areas and the insights into magma origin that can be gained from these variations $[1,2]$. Most such attention has focused on the relatively abundant volcanic rocks in these arcs, although in almost all oceanic arcs, the most acidic rock units are the intrusive bodies [3] .

Puerto Rico, along with the Virgin Islands, form the eastern end of the Greater Antilles, an inactive oceanic island arc. The geologic development of Puerto Rico began with pre-Albian deep-water submarine volcanism, followed in turn by more explosive, shallower-water submarine and terrestrial volcanism $[4,5]$. This volcanic sequence has been divided by Donnelly et al. [4] into an earlier "chemically primitive" group of middle Cretaceous age and a later "chemically more evolved" group that formed from middle Cretaceous to Eocene time. The large intrusive units are associated with the later group. By late Oligocene time volcanism and intrusive activity ceased and the area was partly covered by volcaniclastic and then carbonate sediments.

In a study of the compositional evolution of intrusive rocks in the eastern Greater Antilles, Kesler and Sutter [6] showed that there had been a decrease in $\mathrm{K}_{2} \mathrm{O}$ in the intrusive magmas during approximately the last half of arc evolution from 88 to 38 m.y. ago. The average rate of change of $\mathrm{K}_{2} \mathrm{O}$ content with time was approximately $-0.06 \%$ per million years. In this study, we have obtained high-precision strontium isotopic analyses for three intrusive rocks that represent almost this entire span of time in order to determine whether similar isotopic changes can be observed in this genetically important parameter.

Two of the intrusive rock units tested in this study 
are compositionally anomalous with respect to the most common volcanic and intrusive rocks in an island arc. Whereas the volcanic rocks in the eastern Greater Antilles are largely andesitic [7] and the intrusive rocks are largely quartz dioritic, the Morovis and San Lorenzo units included here are granodioritic. Thus, our data also provide information on whether these more potassic magmas were derived from essentially the same source as the more abundant, less potassic magmas.

\section{Geological setting and characteristics of the intru- sive rocks}

Puerto Rico is at the eastern end of the Greater Antilles island arc, which was active volcanically from late Jurassic or early Cretaceous until Eocene time. This end of the Greater Antilles arc, including the Virgin Islands, Puerto Rico and Hispaniola (Fig. 1), appears to have been built on metamorphosed oceanic crust that yields K-Ar ages of about 125 m.y. [8,9]. Early volcanism in the eastern Greater Antilles was largely deep submarine [4.5] whereas later volcanism took place in a shallow water or terrestrial environment [5]. Intrusive rocks of significant size developed during the later phases of volcanic activity in late Cretaceous and early Cenozoic time and it is these rocks that are included in this study.

Kesler and Sutter [6] have reviewed the distribution, age and major element chemical compositions of intrusive rocks in Puerto Rico and the adjacent Virgin Islands. Of these intrusions, the oldest is the Morovis stock ("MV", Fig. 1), which has a K-Ar age of $88 \mathrm{~m} . \mathrm{y}$. [8]. This stock has a relatively small outcrop area of about $25 \mathrm{~km}^{2}$. It is very homogeneous texturally, exhibits no major element compositional variation, and is a medium-grained, hornblende-biotite monzonite to quartz monzonite. It appears to be coeval with $\mathrm{K}$-rich basaltic rocks of the Rio Orocovis Formation and related volcanic units in central Puerto Rico [10].

The San Lorenzo batholith ("SL", Fig. 1) is the largest intrusive unit in the eastern Greater Antilles, with an outcrop area of about $500 \mathrm{~km}^{2}$. It has been divided into three facies, the oldest of which is thought to be a small diorite-gabbro unit with a $\mathrm{K}$-Ar age of 78 m.y. As noted by Kesler and Sutter [6], parts of this unit appear to be older than $78 \mathrm{~m} . \mathrm{y}$. and little information is available at present on the exact distribution and ages of various mafic rock units in and near the San Lorenzo batholith. For this reason, we have not included these mafic rocks in this study. The bulk of the batholith consists of an extensive granodiorite-quartz diorite unit with a K-Ar age of $73 \mathrm{~m} . \mathrm{y}$, and a smaller quartz diorite unit with a K-Ar

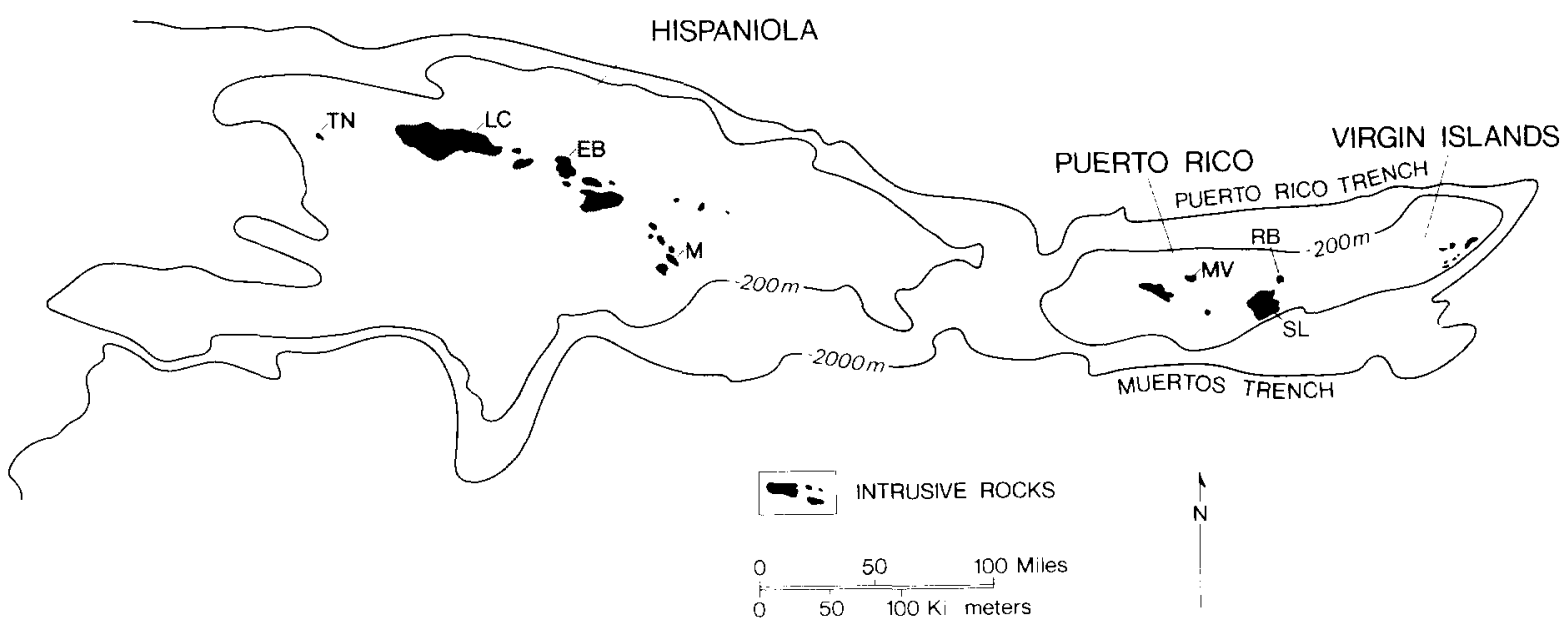

Fig. 1. Schematic geologic and bathymetric map of the eastern Greater Antilles showing the 200-and 2000-m isobaths and the location of intrusive rocks discussed in the text. Puerto Rico: MV = Morovis stock; RB = Rio Blanco stock; $\mathrm{S} 1=\mathrm{San}$ Lorenzo batholith. Hispaniola: $\mathrm{EB}=\mathrm{El}$ Bao batholith; $\mathrm{LC}=$ Loma de Cabrera batholith; $\mathrm{M}=$ Medina stock; $\mathrm{TN}=\mathrm{Terre}$ Neuve stock. 
age of $66 \mathrm{~m} . y$. [8]. Although we can observe textural and major element differences between these two units [6], their $\mathrm{Rb} / \mathrm{Sr}$ characteristics are similar, as is noted in later section. Thus, we have considered the granodiorite-quartz monzonite facies as a single unit here.

The Rio Blanco stock ("RB", Fig. 1) is also a small intrusion, with an outcrop area of about $25 \mathrm{~km}^{2}$. It is largely a hornblende-biotite quartz diorite in composition and has a relatively homogeneous, medium. to coarse-grained texture [11]. The Rio Blanco stock is associated with small, contact-localized copper deposits, although the stock itself is relatively unaltered.

The exact tectonic configuration of the eastern Greater Antilles during the development of these intrusive rocks is not known. Subduction could have taken place from either the Puerto Rico trench on the north or from the Muertos trench on the south (Fig. 1) or both $[12,13]$.

In comparison of the Puerto Rican intrusive rocks to those previously described elsewhere in the Greater Antilles, the Morovis stock has no counterpart; the San Lorenzo batholith is slightly more granodioritic than the El Bao batholith in Hispaniola [9]. The Rio Blanco stock, though much smaller, is similar in composition to the Medina and $\mathrm{El}$ Bao quartz diorites in Hispaniola ("M" and "EB", Fig. 1). Comparison of the data of Kesler et al. [9] and Kesler and Sutter [6] demonstrate that, in general, the intrusive rocks of Puerto Rico are more granodioritic than those to the west in Hispaniola.

\section{Experimental procedures}

Collection procedures used to obtain samples and analytical methods used in the major element chemical analyses reported previously are outlined by Kesler and Sutter [6]. The strontium isotopic geochemistry was determined on rock powders originally prepared for the major element chemical work. These powders were dissolved in an $\mathrm{HF}-\mathrm{HNO}_{3}-\mathrm{HClO}_{4}$ mixture and the strontium separated by cation exchange using a standard procedure. The purified strontium was placed on a rhenium ribbon and the isotopic composition measured using a Varian MAT 260 thermal ionization mass spectrometer. A double fila- ment arrangement was used for the evaporationionization of the sample. A routine analysis consisted of five sets of ten runs, each run consisting of 100 measurements. The standard deviation of the ${ }^{87} \mathrm{Sr} /{ }^{86} \mathrm{Sr}$ ratio is generally $< \pm 0.00003(2 \sigma)$. The rubidium and strontium concentrations were determined by X-ray fluorescence using an ORTEC TEFA system. Replicate analyses indicate a precision of the $\mathrm{Rb} / \mathrm{Sr}$ ratio of $\sim 1 \%$.

\section{Strontium isotopic data for the Puerto Rican intru- sive rocks}

Strontium isotopic and related chemical data on the Morovis, San Lorenzo and Rio Blanco intrusive rocks are given in Table 1. Note that the Morovis stock exhibits an isotopic homogeneity similar to its textural and major element chemical homogeneity. This lack of chemical variation precluded the delineation of a whole-rock isochron for the Morovis data (Fig. 2). Initial ${ }^{87} \mathrm{Sr} /{ }^{86} \mathrm{Sr}$ ratio calculated for the Morovis stock data using an age of $88 \mathrm{~m} . \mathrm{y}$. are very similar, ranging from 0.70361 to 0.70380 and averaging $0.70370 \pm 0.00006$ (6 samples, Table 1$)$. In comparison to other intrusive rocks with relatively high $\mathrm{K}_{2} \mathrm{O}$ abundances, the strontium content of the Morovis stock appears to be somewhat high. However, $\mathrm{K} / \mathrm{Rb}$ ratios average 365 and are well within the expected range for rocks of this type.

The data for the San Lorenzo batholith exhibit a relatively large compositional variation and yield a whole-rock $\mathrm{Rb}-\mathrm{Sr}$ isochron (Fig. 2) with an initial ${ }^{87} \mathrm{Sr} /{ }^{86} \mathrm{Sr}$ ratio of $0.70355 \pm 0.00002$. The age of this isochron is $71 \pm 2 \mathrm{~m} . \mathrm{y}$., which is very close to the $\mathrm{K}$-Ar age of $73 \mathrm{~m}$.y. obtained for the dominant granodiorite-quartz diorite facies of the batholith [6]. Samples PR-71-67A and -67B, which are part of this isochron, were collected from an area mapped as 66m.y.-old quartz monzonite facies. A two-point isochron of these samples gives a data of $70 \pm 3$ m.y. and an initial ratio of $0.70358 \pm 0.00004$ which is identical to the initial ratio of the first isochron. The average calculated initial ratio for the San Lorenzo batholith samples is 0.70355 . In view of the similarity between the $\mathrm{Rb} / \mathrm{Sr}$ geochemistry of these two units, we interpret our data to represent a composite isochron for both the granodiorite-quartz diorite facies of the batholith. 
TABLE 1

Strontium isotopic and related chemical data for the Morovis, San Lorenzo, and Rio Blanco intrusive units, Puerto Rico. The symbols $\mathrm{G}$ and $\mathrm{Q}$ after the San Lorenzo sample numbers refer to the granodiorite-quartz diorite and quartz monzonite phases of the batholith, respectively

\begin{tabular}{|c|c|c|c|c|c|c|c|c|}
\hline Sample No. & $\mathrm{K}_{2} \mathrm{O}^{\mathrm{a}}(w \mathrm{w} . \%)$ & $\mathrm{K} / \mathrm{Rb}$ & $\mathrm{Rb}(\mathrm{p}$ & $\mathrm{Sr}(\mathrm{ppm})$ & ${ }^{87} \mathrm{Sr} /{ }^{86} \mathrm{Sr}$ & ${ }^{87} \mathrm{Rb} /{ }^{86} \mathrm{Sr}$ & Age (m.y.) & $\left({ }^{87} \mathrm{Sr} /{ }^{86} \mathrm{Sr}\right)_{0}{ }^{\mathrm{c}}$ \\
\hline \multicolumn{9}{|l|}{ Morovis Stock } \\
\hline PR-72-115 & 3.7 & 330 & 104 & 756 & $0.70412 \pm 2$ & 0.398 & 88 & $0.70362 \pm 3$ \\
\hline PR-72-117 & 3.8 & 370 & 95 & 751 & $0.70413 \pm 3$ & 0.366 & 88 & $0.70367 \pm 3$ \\
\hline PR-72-119 & 3.7 & 390 & 88 & 753 & $0.70422 \pm 3$ & 0.338 & 88 & $0.70380 \pm 3$ \\
\hline PR-72-121 & 3.9 & 380 & 95 & 812 & $0.70418 \pm 3$ & 0.338 & 88 & $0.70376 \pm 3$ \\
\hline PR-72-123 & 3.9 & 360 & 101 & 737 & $0.70424 \pm 2$ & 0.396 & 88 & $0.70375 \pm 3$ \\
\hline PR-72-125 & 4.2 & 360 & 107 & 731 & $0.70414 \pm 2$ & 0.423 & 88 & $0.70361 \pm 3$ \\
\hline \multicolumn{9}{|c|}{ San Lorenzo Batholith } \\
\hline PR-71-61-G & 1.8 & 430 & 39 & 433 & $0.70377 \pm 2$ & 0.26 & 73 & $0.70350 \pm 3$ \\
\hline PR-71-67A-Q & 3.6 & 480 & 69 & 446 & $0.70402 \pm 2$ & 0.45 & 66 & $0.70360 \pm 3$ \\
\hline PR-71-67B-Q & NA & & 88 & 98 & $0.70615 \pm 3$ & 2.60 & 66 & $0.70372 \pm 11$ \\
\hline PR-71-71B-G & 4.5 & 480 & 86 & 80 & $0.70664 \pm 2$ & 3.11 & 73 & $0.70342 \pm 11$ \\
\hline PR-71-90-G ${ }^{\mathrm{d}}$ & 2.0 & 540 & 34 & 363 & $0.70383 \pm 5$ & 0.27 & $(70)$ & $0.70355 \pm 5$ \\
\hline PR-72-100-G & 2.8 & 550 & 47 & 376 & $0.70393 \pm 2$ & 0.36 & 73 & $0.70356 \pm 3$ \\
\hline \multicolumn{9}{|c|}{ Rio Blanco Stock } \\
\hline PR-71-83 & 1.2 & 330 & 34 & 229 & $0.70435 \pm 2$ & 0.43 & 45 & $0.70407 \pm 3$ \\
\hline PR-71-87 & 1.3 & 370 & 33 & 232 & $0.70438 \pm 2$ & 0.41 & 45 & $0.70411 \pm 3$ \\
\hline PR-72-109 & 0.8 & 340 & 22 & 262 & $0.70410 \pm 3$ & 0.24 & 45 & $0.70394 \pm 3$ \\
\hline PR-72-111 & 2.4 & 620 & 36 & 242 & $0.70447 \pm 2$ & 0.43 & 45 & $0.70419 \pm 2$ \\
\hline
\end{tabular}

${ }^{\mathrm{a}} \mathrm{K}_{2} \mathrm{O}$ values from S.E. Kesler, XRF total-rock analyses.

${ }^{\mathrm{b}}$ Normalized to ${ }^{86} \mathrm{Sr} /{ }^{88} \mathrm{Sr}=0.11940 ; \mathrm{NBS} 987 \mathrm{SrCO}_{3}$ standard, ${ }^{87} \mathrm{Sr} /{ }^{86} \mathrm{Sr}=0.71037 \pm 0.00002(2 \sigma)$. $N=9$; Eimer and Amend $\mathrm{SrCO}_{3}$ standard, ${ }^{87} \mathrm{Sr} /{ }^{86} \mathrm{Sr}=0.70820 \pm 0.00002(2 \sigma), N=2$; all uncertainties are $2 \sigma$.

${ }^{c}$ Initial ${ }^{87} \mathrm{Sr} /{ }^{86} \mathrm{Sr}$ ratio calculated assuming $\lambda\left({ }^{87} \mathrm{Rb}\right)=1.42 \times 10^{-11} \mathrm{yr}^{-1}$.

$\mathrm{d}$ There is some uncertainty concerning the phase to which this sample belongs.

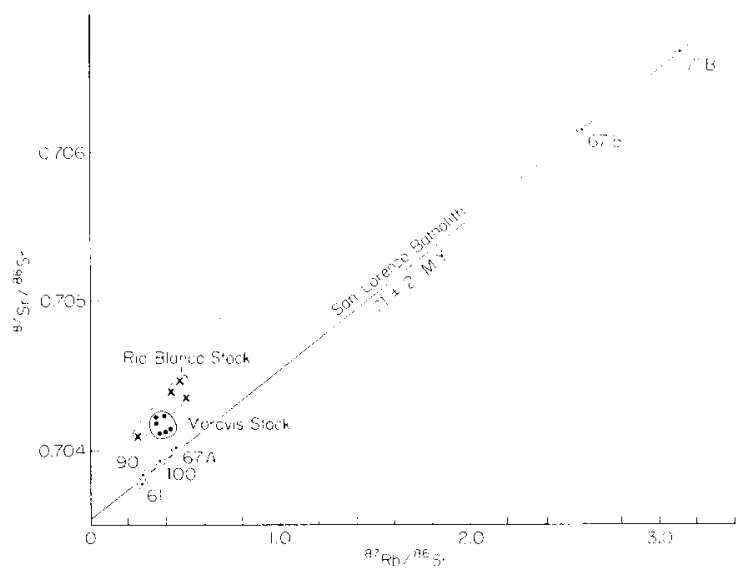

Fig. $2 .{ }^{87} \mathrm{Sr} /{ }^{86} \mathrm{Sr}$ vs. ${ }^{87} \mathrm{Rb} /{ }^{86} \mathrm{Sr}$ for the Morovis, San Lorenzo and Rio Blanco intrusive rocks. Note that the San Lorenzo data form a isochron whereas the other two units form clusters.
The four available samples from the Rio Blanco stock exhibit relatively small variation in their present. day isotopic composition of strontium (0.703840.70419 ). A suggestion of a linear trend is generated by these samples on an isochron plot, yielding a slope equivalent to approximately 300 m.y. Analysis of additional samples with a greater spread in the $\mathrm{Rb}$ / Sr ratio is necessary as an age of this magnitude is markedly different from the K-Ar age of 45 m.y. obtained for the stock [8] as well as being incompatible with geologic evidence [11]. The average calculated initial ${ }^{87} \mathrm{Sr} /{ }^{86} \mathrm{Sr}$ ratio for the four Rio Blanco samples is $0.70408 \pm 0.00009$.

The data summarized here indicate that, as a function of time, the initial ${ }^{87} \mathrm{Sr} /{ }^{86} \mathrm{Sr}$ ratios for these magmas (San Lorenzo, $0.70355 \pm 0.00002$; Morovis, $0.70370 \pm 0.00006)$ remained nearly the same or, 
at most, increased slightly during the generation of the Eocene Rio Blanco magma $(0.70408 \pm 0.00009)$. In contrast, average $\mathrm{K}_{2} \mathrm{O}$ and $\mathrm{Rb}$ contents of the three intrusions decreased steadily with time (Table 1). The $\mathrm{Sr}$ content is highest for the Morovis stock, which is the oldest; the two younger intrusive units have similar $\mathrm{Sr}$ concentrations. If the parental magmas for these intrusive magmas had been similar in bulk composition, crystal fractionation would have yielded generally similar increases in $\mathrm{K}_{2} \mathrm{O}$ and $\mathrm{Rb}$ contents and a decrease in $\mathrm{Sr}$ content with time. The fact that the $\mathrm{K}_{2} \mathrm{O}, \mathrm{Rb}$ and $\mathrm{Sr}$ contents of the three intrusive magmas are so different suggests that their parental magma compositions were also different. In contrast, the general similarity of initial ${ }^{87} \mathrm{Sr} /{ }^{86} \mathrm{Sr}$ ratios in the three intrusions indicates that all three may have been derived from similar source materials but by different conditions of partial melting and/or fractional crystallization.

\section{Comparison with other oceanic and continental margin arc systems}

The similarity of strontium isotopic and major element data for the Puerto Rican intrusions and other intrusive rocks in the Greater Antilles supports the conclusion that intrusive rocks ranging from monzonite to quartz diorite were derived from sources with similar ${ }^{87} \mathrm{Sr} /{ }^{86} \mathrm{Sr}$ ratios. Kesler et al. [9] obtained calculated initial ratios of $0.7030-0.7037$ for the Loma de Cabrera granodioritic and El Bao quartz dioritic batholiths in Hispaniola ("LC" and "EB", Fig. 1). Feigenson [14] subsequently reported that the Loma de Cabrera batholith yields an isochron with an initial ratio of 0.7036 . Results for the Medina quartz diorite stock ("M", Fig. 1) were more variable but suggest a similarly low initial ratio. Jones et al. [15] reported an average calculated initial ratio of 0.7036 for the granodioritic Terre Neuve stock in Hispaniola ("TN", Fig. 1) and similar results $(0.7033,0.7034)$ for the Above Rocks granodioritic stock in Jamaica. Thus, for the Greater Antilles, intrusive rocks ranging from quartz diorite to granodiorite have initial ${ }^{87} \mathrm{Sr} /{ }^{86} \mathrm{Sr}$ ratios of 0.7035 to about 0.7040 .

Comparison of the results from the Greater Antilles with results obtained from other island arcs and con- tinental margin areas (see table 1 in Kay et al. [16]) shows that: (1) most oceanic island arc volcanic rocks have initial ${ }^{87} \mathrm{Sr} /{ }^{86} \mathrm{Sr}$ ratios very similar to those observed for the intrusive rocks in the Greater Antilles, whereas (2) intrusive and volcanic rocks from continental margin areas exhibit higher initial ${ }^{87} \mathrm{Sr} /{ }^{86} \mathrm{Sr}$ ratio. The magmas at the continental margins contain a greater proportion of intermediate to granitic compositions than do the island arc magmas. Thus, although derivation of large volumes of granodioritic intrusive rocks at continental margins involves sources that contribute significant amounts of radiogenic strontium, no such source is necessary to generate the granodioritic intrusions of oceanic island arc areas.

\section{Source of the intrusive magmas}

The Puerto Rico intrusive magmas could have been derived from: (1) subducted oceanic or continental sediments; (2) subducted ocean floor basalt with or without seawater contamination; (3) the mantle wedge above the subduction zone with or without additions from the subduction zone; or (4) some combination of these sources. As noted by Kay et al. [16] and Hawkesworth et al. [17], sedimentary contributions to magma systems are best detected with $\mathrm{Pb}$ isotope data. Although no such data are presently available for the Puerto Rican intrusive rocks, $\mathrm{Pb}$ isotopic data for mineral deposits derived from these rocks (Cumming and Kesler [18] and unpublished data) do not indicate a recognizable and thus significant sedimentary contribution. Selection between the remaining two sources, oceanic crust or the mantle wedge, is hampered by the absence of $\mathrm{Nd}$ isotopic data, although we favor the mantle wedge as the principal magma source for the following reasons. The pattern of decreasing $\mathrm{K}_{2} \mathrm{O}$ and $\mathrm{Rb}$ with time would be expected for episodic partial melting of a single source but it is more difficult to account for if the subducted slab was undergoing melting. The slight increase in ${ }^{87} \mathrm{Sr} /{ }^{86} \mathrm{Sr}$ ratio for the Rio Blanco magma could reflect additions of ${ }^{87} \mathrm{Sr}$ to the mantle wedge from volatiles rising from the subducted slab or from minor contamination by crustal melting. If this line of reasoning is correct, the principal reason for the compositional evolution of the Puerto Rican intrusive rocks was the gradual depletion of $K$ and $R b$ from the partial melting zone in the mantle wedge. 


\section{Acknowledgements}

The isotopic analyses were done in the Geochronology Laboratory and $\mathrm{Rb}$ and $\mathrm{Sr}$ determinations in the X-ray Laboratory; both are in the Analytical Research Section, Research and Development Department, Conoco Inc. The support of Conoco Inc. through the use of its facilities in this study is gratefully acknowledged. Suggestions made by R.S. Thorpe and a second but unknown reviewer have much improved this paper. Their help is greatly appreciated.

\section{References}

$1 \mathrm{H}$. Kuno, Lateral variation of basalt magma type across continental margins and island arcs, Bull. Volcanol. 29 (1966) 195-222.

2 W.R. Dickinson, Potash-depth $(\mathrm{K} h)$ relations in continental margin and intra-oceanic magmatic arcs, Geology 3 (1975) $53-57$.

3 S.E. Kesler, L.M. Jones and R.L. Walker, Intrusive rocks associated with porphyry copper mineralization in island arc areas, Econ. Gcol. 70 (1975) $515-526$.

4 T.W. Donnelly, J.J.W. Rogers, P, Pushkar and R.L. Armstrong, Chemical evolution of the igneous rocks of the eastern West Indies, in: Caribbean Geophysical, Tectonic and Petrologic Studies. Geol. Soc. Am. Mem. 130 (1971) 181-224.

5 L. Glover III, Geology of the Coamo area, Puerto Rico, and its relation to the volcanic arc-trench association, U.S. Geol. Surv. Prof. Paper 636: 102 pp.

6 S.E. Kesler and J.F. Sutter, Compositional evolution of intrusive rocks in the eastern Greater Antilles, Geology 7 (1979) 197-200.

7 L.G. Lidiak, Spatial and temporal variations of potassium in the volcanic rocks of Puerto Rico, VI Conf. Geol. del Caribe Memorias, Margarita, Venezuela (1972) 203-209.
8 D.F. Cox, R.F. Martin, J.W. M'Gonigle, D.H. Mclntyre and C.L. Rogers, Potassium argon geochronology of some metamorphic, igneous and hydrothermal events in Puerto Rico and Virgin Islands, U.S. Geol. Surv. J. Res. 5 (1977) $689-703$.

9 S.E. Kesler, J.F. Lewis, L.M. Jones and R.L. Walker, Early island-arc intrusive activity, Cordillera Central, Dominican Republic, Contrib. Mineral. Petrol. 65 (1977) 91-99.

10 W.T. Jolly, Potassium-rich igneous rocks from Puerto Rico, Geol. Soc. Am. Bull. 82 (1971) 399-408.

11 V.M. Seiders, Geologic map of the El Yungue quadrangle, Puerto Rico, U.S. Geol. Surv. Misc. Geol. Invest. Map I-658 (1971).

12 J.W. Ladd, Relative motion of South America with respect to North America and Caribbean tectonics, Geol. Soc. Am. Bull. 87 (1976) 969-976.

13 B.T. Malfait and M.G. Dinkelman, Circum-Caribbean tectonic and igneous activity and the evolution of the Caribbean plate, Geol. Soc. Am. Bull. 83 (1972) 251272.

14 M.D. Feigenson, The petrology and geochemistry of the Loma de Cabrera batholith of the western Dominican Republic, M.Sc. Thesis, George Washington University, Washington, D.C. (1978) 99 pp.

15 L.M. Jones, R.L. Walker, S.E. Kesler and J.F. Lewis, Strontium isotope geochemistry of late Cretaceous granodiorites, Jamaica and Haiti, Greater Antilles, Earth Planet. Sci. Lett. 43 (1979) 112-116.

16 R.W. Kay, S.S. Sun and C.N. Lee-Hu, Pb and $\mathrm{Sr}$ isotopes in volcanic rocks from the Aleutian Islands and Pribiloff Islands, Alaska, Geochim. Cosmochim. Acta 42 (1978) $263-274$.

17 C.J. Hawkesworth, M.J. Norry, J.C. Roddick, P.E. Baker, P.W. Francis and R.S. Thorpe, ${ }^{143} \mathrm{Nd} /{ }^{144} \mathrm{Nd},{ }^{87} \mathrm{Sr} /{ }^{86} \mathrm{Sr}$, and incompatible element variations in calc-alkaline andesites and plateau lavas from South America, Earth Planet. Sci. Lett. 42 (1979) $45-57$.

18 G.L. Cumming and S.E. Kesler, Source of lead in Central American and Caribbean mineralization, Earth Planet. Sci. Lett. 31 (1976) 262-268. 